\title{
PRELIMINARY INVESTIGATION ON THE ATMOSPHERIC DISPERSION OF POLLUTANTS DUE TO FERRAZ FIRE
}

http://dx.doi.org/10.4322/apa.2014.091

\author{
Heitor Evangelista*, Eduardo Delfino Sodré \& Alexandre Castagna Mourão e Lima
}

Laboratório de Radioecologia e Mudanças Globais, Universidade do Estado do Rio de Janeiro (UERJ), Pav. Haroldo L. Cunha/Subsolo, Rua São Francisco Xavier 524, Maracanã, 20550-013 Rio de Janeiro, RJ, Brazil.

*e-mail: evangelista.uerj@gmail.com

\begin{abstract}
Here we present a summary of the atmospheric modeled data for gas and total particulate matter dispersion and deposition due to the fire at Ferraz Station on February 25 $5^{\text {th }}$ 2012. The main purpose is to permit a preliminary diagnosis of the main areas potentially impacted in Admiralty Bay and vicinities for purposes of future decision-making and scientific planning. In this way enable an investigation of the area that came under the impact of the fire emissions and better detail the levels of contamination of biotic and abiotic components of the local environment. This present version of the model takes into account the meteorological data acquired at the time of the fire, as well as observational records and the geomorphology. The great uncertainty assigned to the model refers to the emissions factor due to the high complexity of materials present in Ferraz Station and a subjective estimate of the temperature of the materials ignited during the fire. Thus, the basic function of the model is to describe the spatial behavior of the plume of pollutants and not necessarily the absolute values of the deposition fluxes.
\end{abstract}

Keywords: Atmospheric Dispersion, Fire at Comandante Ferraz, Atmospheric Impact

\section{Introduction}

Although the summer climatic regime at King George Island is predominantly warm and wet with average air temperature reaching near $0^{\circ} \mathrm{C}$ and frequent rainfall, the indoor ambience of the scientific stations in Antarctica is typically dry due to the use of heating systems. In addition, scientific stations also support laboratory work and the use of large quantities of combustible and inflammable insulation materials. This makes scientific stations very vulnerable to outbreaks of fire, even in the summer season. The fire at the Comandante Ferraz Brazilian Antarctic Base occurred on February $25^{\text {th }}, 2012$, and destroyed approximately $70 \%$ of the research station. The fire broke out in the machine room housing the power generators. Basically, all the central core of the base, where the installations were concentrated (with the exception of the atmospheric and chemistry laboratories built apart of the complex), were lost. Therefore, it is estimated that a large quantity of VOCs and aerosols containing chemical ingredients, heavy metals and black carbon derived from the paintwork, several types of plastics, metal shelters, electronic, electric and wood materials were released to the local atmosphere. In order to investigate the geographical amplitude of the impact caused by the smoke plume of particulate matter and gases from the fire at Ferraz Station, we have modeled the atmospheric dispersion for the short scale of Admiralty Bay, and for the regional scale of the Shetland Islands. This would allow future investigation on environmental changes and bioaccumulation along the pathways of the plume dispersion and deposition. This would also help with defining non-impacted sites to be used as background levels and the future impacts associated with resuspension processes as a result of snow drifts and melting.

\section{Materials and Methods}

For the purpose of modeling the atmospheric dispersion and deposition, we have used the following set of data: (1) meteorological data from Ferraz Station corresponding to the

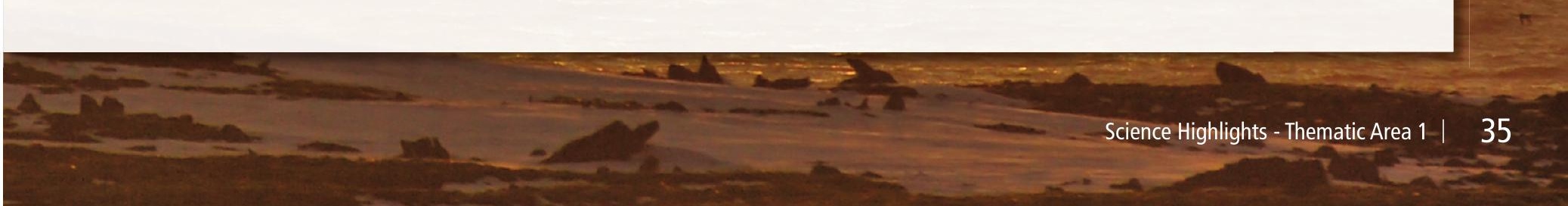


date of the fire; (2) the local high resolved geomorphological database (that constrains the pollutant plume development); (3) reports on the fire event (photographs of the fire and burning process, estimates of total material released). Two models were employed in this study: (1) the AERMOD, from the EPA (Environmental Protection Agency)/USA and modified by the Lakes Environmental Software, version 6.7.1. It is an improved Gaussian model that incorporates details of the morphology; (2) The HYSPLIT (HYbrid Single-Particle Lagrangian Integrated Trajectory) model, available by NOAA/NASA, which is a complete system for computing simple air parcel trajectories to complex dispersion and deposition simulations. The recently released version used has upgrades that include improved advection algorithms and updated stability and dispersion equations. Both model's default configuration assumes a 3-dimensional particle distribution (horizontal and vertical).

\section{Meteorological and geomophological database}

Taking into account the atmospheric conditions at Ferraz on February $25^{\text {th }}$, we observed that between 0:00hrs and 12:00hrs (GMT), surface winds were in the interval 0.6-6.4 $\mathrm{m} / \mathrm{s}$. By the second half of the day, they became stronger reaching $9.6 \mathrm{~m} / \mathrm{s}$ coming predominantly from the SWW and WNW sectors of Admiralty Bay. Different stability classes in the atmosphere can occur based on how large or small the air temperature difference is between the air parcel and the surrounding environment. For dispersion modeling purposes, the stability class is classified into six categories (from $\mathrm{A}$ to $\mathrm{F}$ ) based on the following parameters: wind intensity, daily solar radiation and cloudiness. These stability classes are referred to as Pasquill-Gifford-Turner stability classes.

\section{Modeling pollutant plume dispersion}

For the case of the Ferraz fire we modeled the atmospheric concentration and deposition of total particulate matter and $\mathrm{SO}_{2}$. As for the choice of timescale, we opted for integration in 24 hours, which is the average concentration of the investigating period. We chose to use the mode "terrain height" where algorithms are applied to consider the topography of the region.
An estimate of the plume of smoke height produced by the fire at Ferraz Station was based on eye witness reports, having as reference the altitude of "Morro da Cruz" elevation that is $\sim 250 \mathrm{~m}$. Thus, the height of the plume of smoke was estimate at $450 \mathrm{~m}$.

\section{Modeling the local dispersion}

For the local dispersion of pollutants we have used the AERMOD Gaussian plume model. The model was firstly developed by EPA (Environmental Protection Agency of USA) and then modified by Lakes Environmental Software Company, commercially released as version 6.7.1 (Vidal, 2008). This version allows the use of geomorphologic database to calculate the atmospheric concentrations and deposition on surfaces. The model assumes that during a steady state condition, horizontally and vertically, the concentrations of contaminants follow a Gaussian distribution, whereby the length of the smoke plume is determined by the scattering coefficients which are based on the Pasquil stability classes. The transport of pollutants in the atmosphere is intrinsically related to the dynamics of the winds either by advection or turbulent diffusion. Briefly, advection is the horizontal movement of a portion of air which carries the pollutants, whereas the turbulent diffusion spreads pollutants within a three-dimensional manner. The Gaussian plume is a result of the analytical integration of the transport equation, when one adopts some simplifying assumptions such as homogeneous and stationary turbulence, flow steady emission, constant wind direction and where chemical species are stable. It is also considered that there are no losses of the particulates due to physical mechanisms, chemical reactions or biological activity. In the model the smoke source is located at $62.085^{\circ} \mathrm{S}$ and $058.403^{\circ} \mathrm{W}$ at $15 \mathrm{~m}$. The local topography was inserted in the model in the form of coordinates "xyz" referenced in "Geodetic Datum WGS 84." The AERMOD simulates the smoke plume depending on the characteristics of the land according to a weighted sum of two limit states: the plume horizontally collides with the ground and the plume follows the shape of the terrain. Figure 1 depicts the basic concept used in the model and the equation represents the total concentration in this approach. 


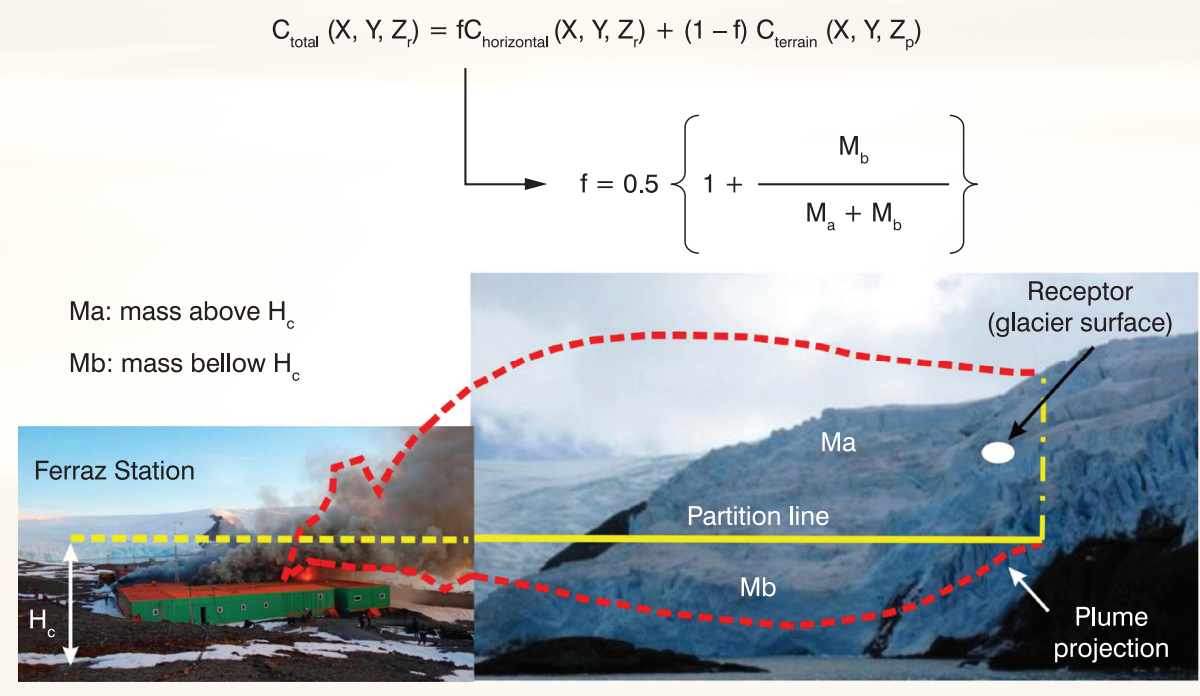

Figure 1. (Upper part) Components of pollutant concentrations along the pathway of the smoke plume. The term on the left is the total concentration; the first contribution of the right side corresponds to the horizontal plume that shocks with the ground, while during the second term the contribution of the plume accompanies the ground. The variable $Z_{p}$ corresponds to the height from the ground and $Z_{r}$ corresponds to the height from the origin of the coordinate system. The variable $f$ is the mass of pollutant that will follow the first limit state while the complement (1-f) corresponds to the fraction that will deviate vertically from the obstacle. (Bottom part) simplified illustration of AERMOD parameterizations.

In addition to the Admiralty Bay plume dynamics, we have detailed the atmospheric concentrations over the Keller Peninsula, since it is a site of great local ice free environment where the terrestrial biota and birds are under long-term monitoring. Therefore, in the AERMOD model we have used a uniform Cartesian grid with a total dimension of $\sim 24,000 \mathrm{~m} \times 20,000 \mathrm{~m}$ in the case of Admiralty Bay, defining 441 squared pollutant ending points. For Keller Peninsula we have applied a grid of $\sim 3,486 \mathrm{~m} \mathrm{x} \mathrm{2,263} \mathrm{m} \mathrm{with} 441$ ending points of $113 \mathrm{~m} \mathrm{x} 174 \mathrm{~m}$.

\section{Modeling the regional dispersion}

Within the regional context which encloses the South Shetland Islands and surrounding oceans, we have used the HYSPLIT (HYbrid Single-Particle Lagrangian Integrated Trajectory)/NOAA model that is a complete system for computing simple air parcel trajectories to complex dispersion and deposition simulations. Recent upgrades of the model include enhancements provided by a number of different contributors. Some of the new features include improved advection algorithms, updated stability and dispersion equations. Hysplit computes the advection of a single pollutant particle, or simply its trajectory. The model's default configuration assumes a 3-dimensional particle distribution (horizontal and vertical). In the present case, the model assumes that the station had approx. 2,600 $\mathrm{m}^{2}$ and $70 \%$ was burned down $\left(1,820 \mathrm{~m}^{2}\right)$. We also considered a mean aerosol size of 2.5 micron with density $2.25 \mathrm{~g} / \mathrm{cc}$ (graphite) and sphericity of 1 (spherical). Model was forced by GDAS meteorological data and run for 24 hours with 24 hours of continuous emission.

\section{Discussion}

Observations and data presented here point to a direct impact of the pollutant plume produced by Ferraz fire. The event took place during a meteorological condition characterized predominantly by a neutral (D) class atmospheric stability, according to Pasquill-Giffort-Turner classification. The East side of Keller Peninsula, where the Brazilian station was built, seems to be more affected by the plume dispersion than the West side (Figure 2). 


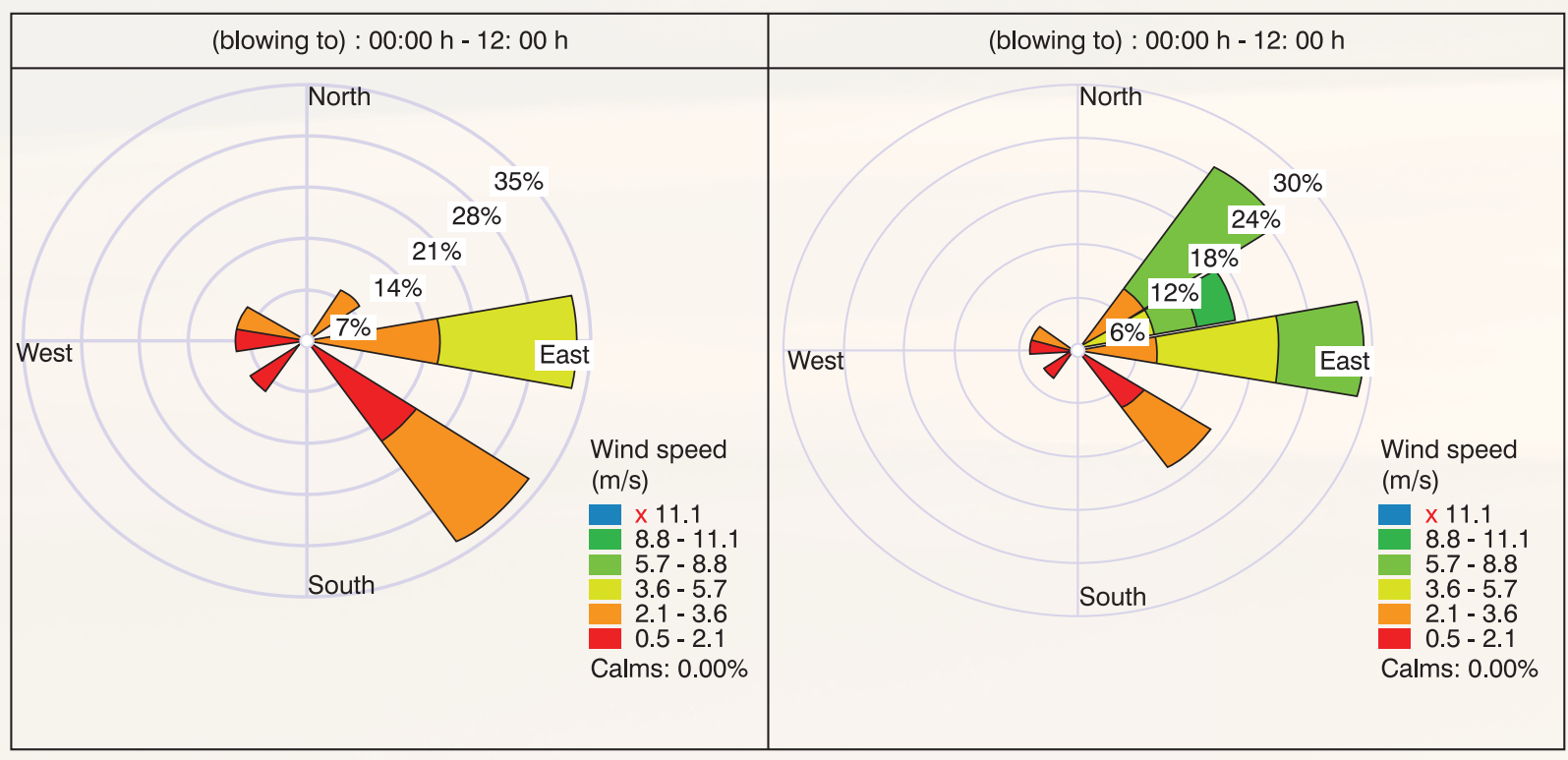
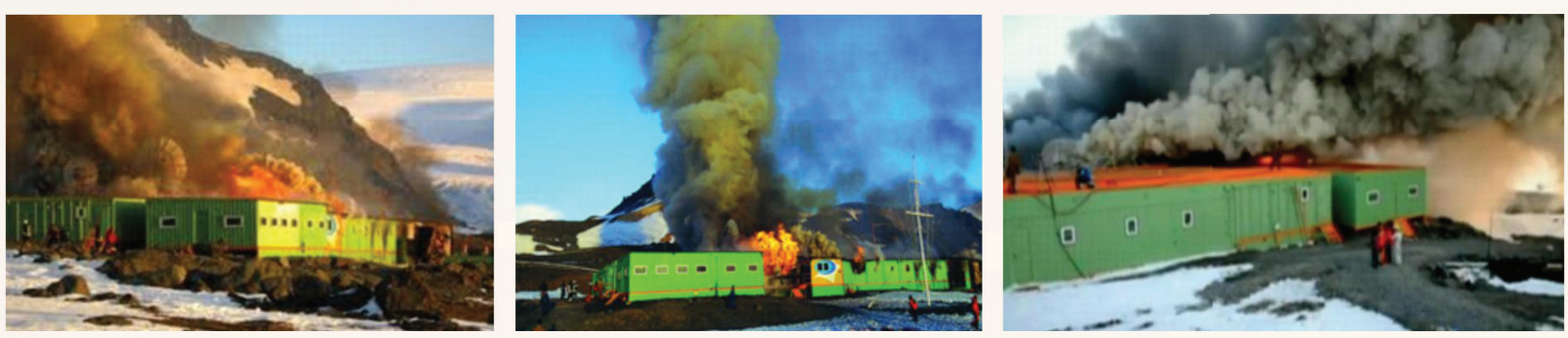

Figure 2. (Upper part) wind rose during the day of Ferraz fire/ (bottom) Fire and smoke rise from Ferraz station (Handout photo released by the Chilean Navy).

\section{Local dispersion of pollutants}

Considering the uncertainties of the total quantity of emissions released to the atmosphere during the Ferraz fire (as well as its variability along the event), the practical handling of the model outputs should be observed with caution. We consider that it is safer for users to base their work on the definition of areas impacted by the plumes pointed out by the model than the atmospheric concentrations and deposition flux estimated here. In the model we assumed an emission rate in the order of $10 \mathrm{~g} / \mathrm{m}^{2} \mathrm{~s}$, resulting in $65,520 \mathrm{~kg} / \mathrm{h}$. By running the model for a time base of 24 hours, we found approximately 1,573 tons of particulate matter emitted. Contour lines of atmospheric concentration obtained for Ferraz fire indicated that the area of greatest influence of fire by-products (gases and particulate matter) emitted, was the East Sector of Keller
Peninsula, mainly the Martel Inlet and Stenhouse and Ulman Peninsula. A second component of the impact was also observed in the Southwest sector towards Ezcurra Inlet, reaching the glacier Warszawa as well as the Southeast Sector reaching the dome of glacier Krakow, Figure 3 (left). AERMOD result for atmospheric deposition depicts a strong impact at Martel inlet, Figure 3(right). This is probably the most impacted site at Admiralty Bay from before the fire. Martel inlet is a place where all logistics of PROANTAR take place and several activities are potentially able to impact that site such as the transport of large quantities of oil, release of biological and chemical residues of Ferraz, etc.

For Keller Peninsula, the most preserved sector from the fire emissions was the NW - N sector (Figure 4). This occurred as a result of the geomorphology of the peninsula. The model evidenced that the plume migration was 

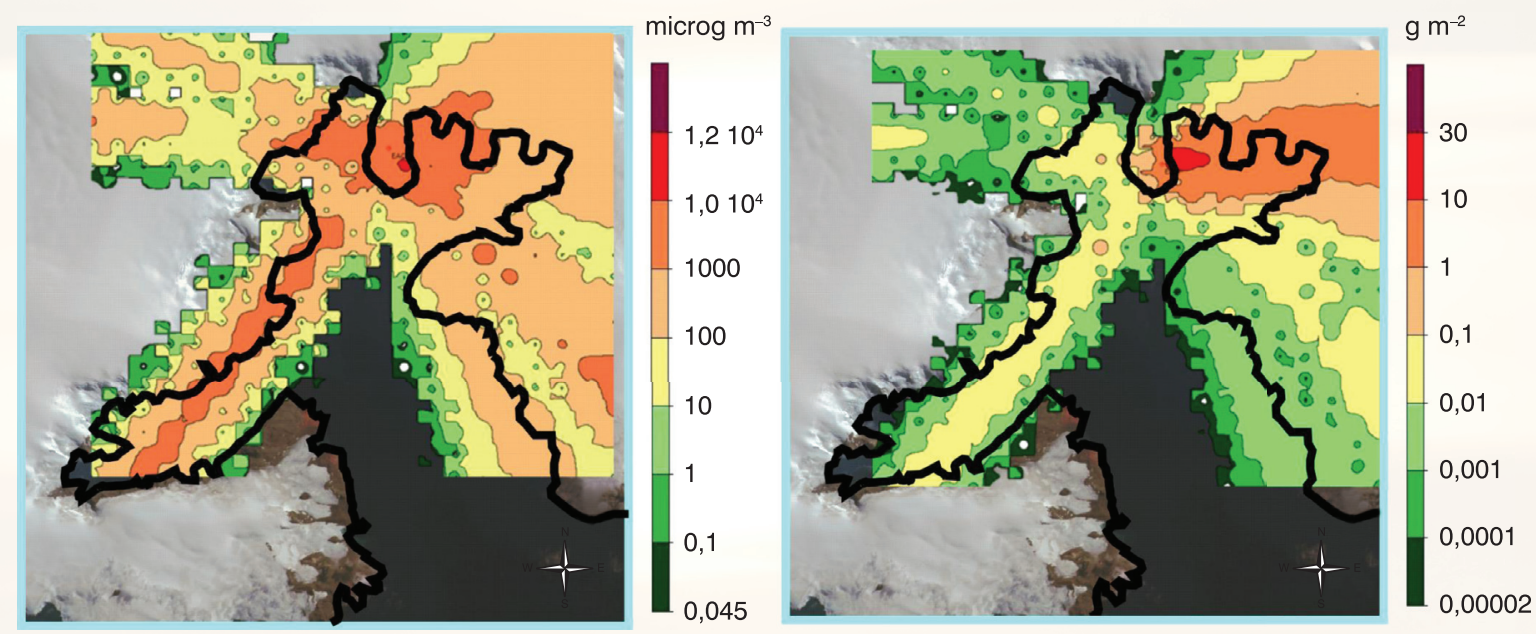

Figure 3. (Left) Smoke dispersion at Admiralty Bay during the day of Ferraz fire (Scenario calculated for gases - $\mathrm{SO}_{2}$ as reference). (Right) Deposition pattern for particulate matter at Admiralty Bay due to Ferraz fire.

constrained by the topographic lines between $\sim 50-100 \mathrm{~m}$, so that the sites of higher elevation near the fire point were probably less affected. An opposite situation was observed for the glaciers in the East side of Martel Inlet due to the rise of the plume during its displacement.

\section{Regional dispersion of pollutants}

The Hysplit model showed that Ferraz plume travelled through King George Island reaching the Drake Channel, but transporting very low concentrations even considering the total particulate matter. The high winds at the tip of the Antarctic Peninsula and the absence of obstacles were responsible for a rapid dispersion in the NE-E direction of King George Island, Figure 5.

\section{Conclusion}

A comparison between the scenarios of dispersion and deposition of Ferraz fire by-products and the areas of greatest terrestrial biodiversity at Admiralty Bay (located in the South Sector) indicates that they do not fully overlay. The Southern side of the Admiralty Bay has been recognized as an Important Bird Area (IBA), since it supports breeding colonies of several seabirds, including penguins, petrels, Snowy Sheathbills, Kelp Gulls, Antarctic Terns and skuas. Our preliminary evaluation indicates that the regions of larger local terrestrial biodiversity were relatively more preserved from the fire byproducts via direct atmospheric dispersion due to the weather characteristics prevailing during the fire event. Nevertheless, considering the complexity of the dispersion and deposition in the polar environment where resuspension and snow drifts are parameters to be considered (Leal et al., 2008), the fjord structure of Admiralty Bay that induces changes in wind direction constantly inside and the uncertainties in the rate of particulate matter emissions along the fire event, it is clear that a deeper analysis should be conducted in order to reach a more precise conclusion on the magnitude of the atmospheric impact.

\section{Acknowledgements}

This work is product of INCT-Criosfera and integrates the National Institute of Science and Technology Antarctic Environmental Research (INCT-APA) that receives scientific and financial support from the National Council for Research and Development (CNPq process: $\mathrm{n}^{\circ}$ 574018/2008-5) and Carlos Chagas Research Support Foundation of the State of Rio de Janeiro (FAPERJ $n^{\circ}$ E-16/170.023/2008). The authors also acknowledge the support of the Brazilian Ministries of Science, Technology and Innovation (MCTI), of Environment (MMA) and InterMinistry Commission for Sea Resources (CIRM). 


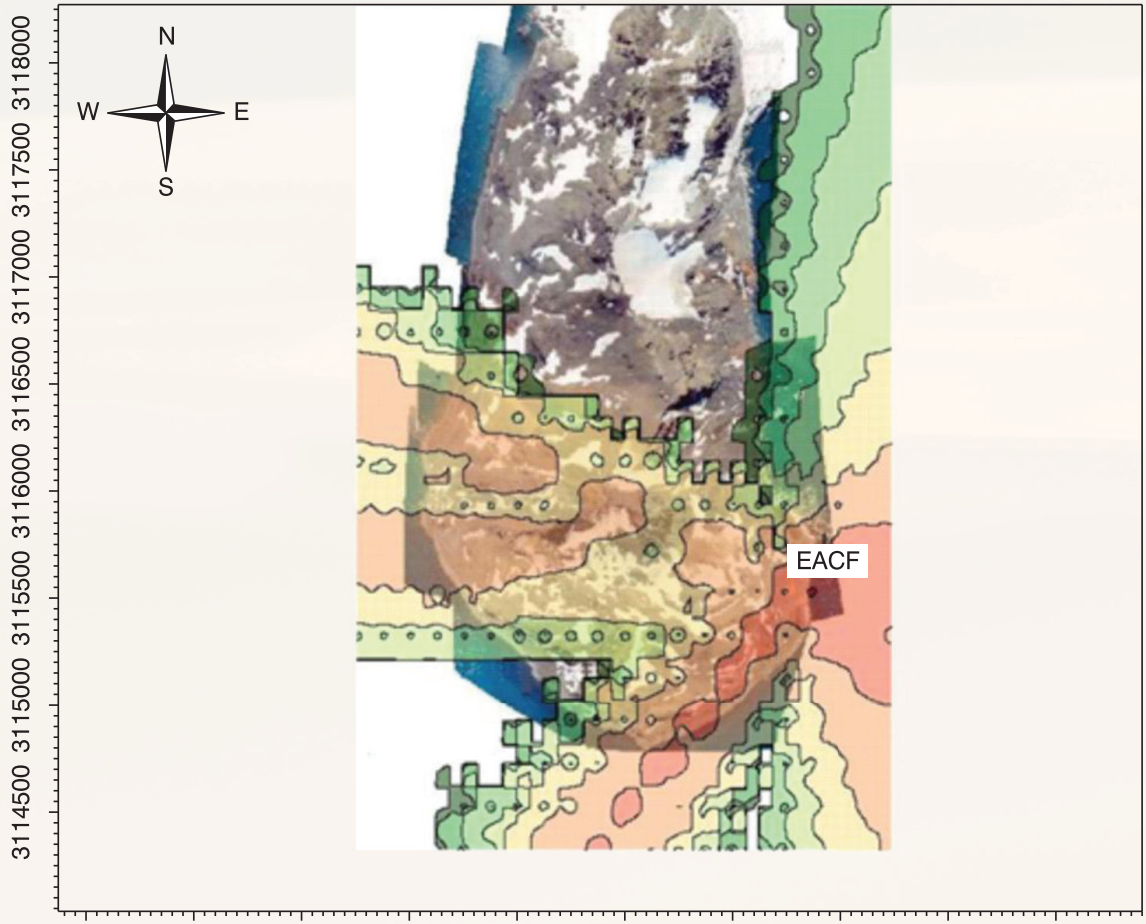

$\mathrm{ug} / \mathrm{m} \wedge 3$

$\begin{array}{llllllllll}424000 & 424500 & 425000 & 425500 & 426000 & 426500 & 427000 & 427500 & 428000 & 428500\end{array}$

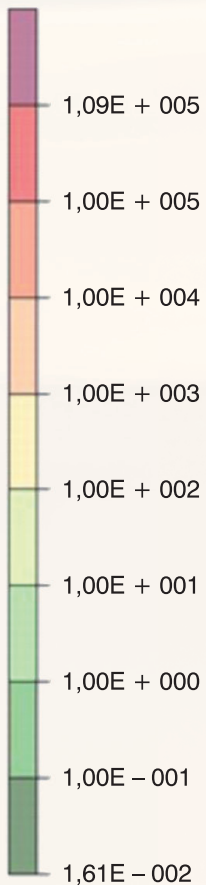

UTM east (m)

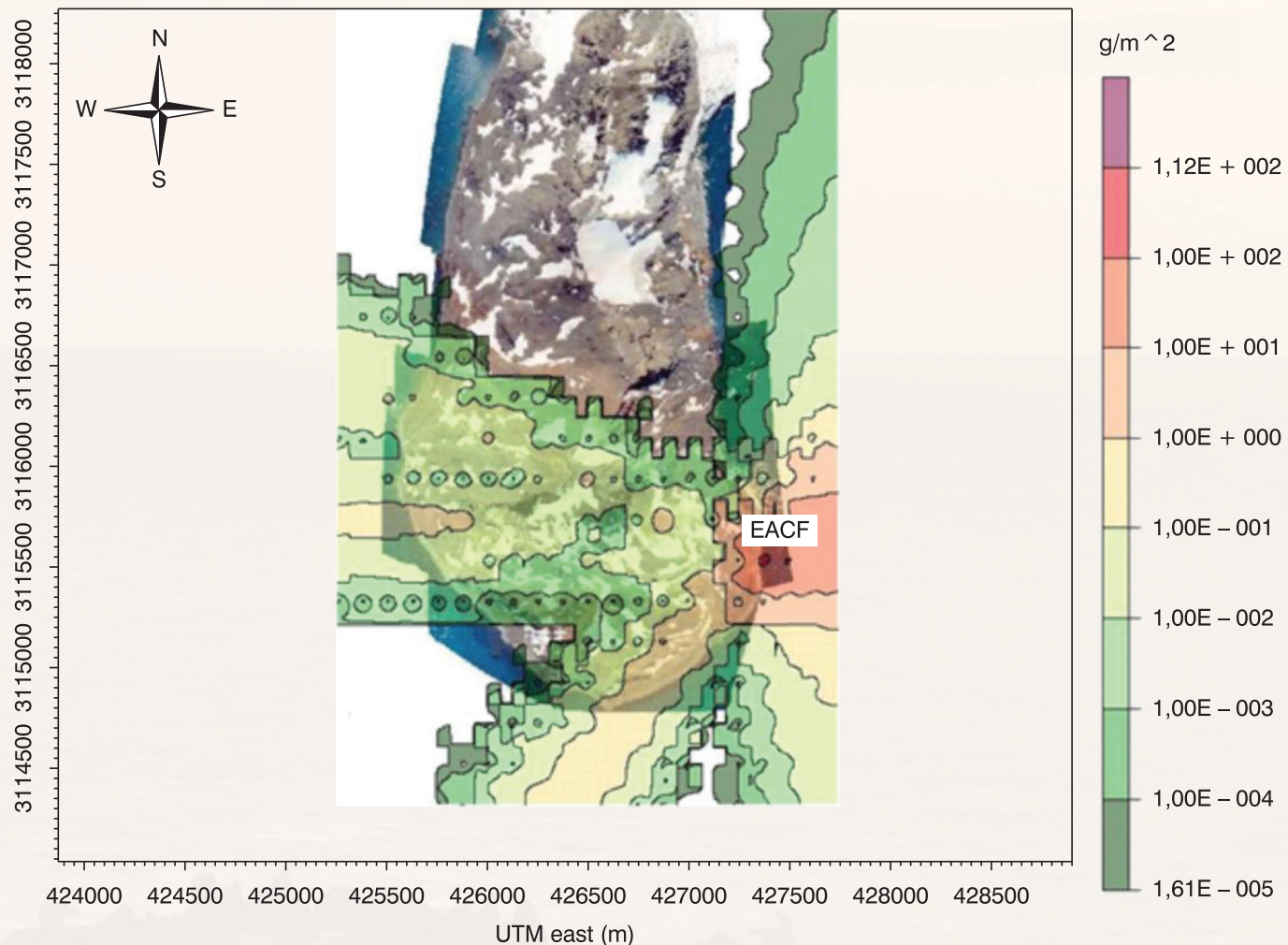

Figure 4. (Left) Smoke dispersion at Peninsula Keller during the day of Ferraz fire (Scenario calculated for gases - $\mathrm{SO}_{2}$ as reference). (Right) Deposition pattern for particulate matter due to Ferraz fire at Keller Peninsula. 

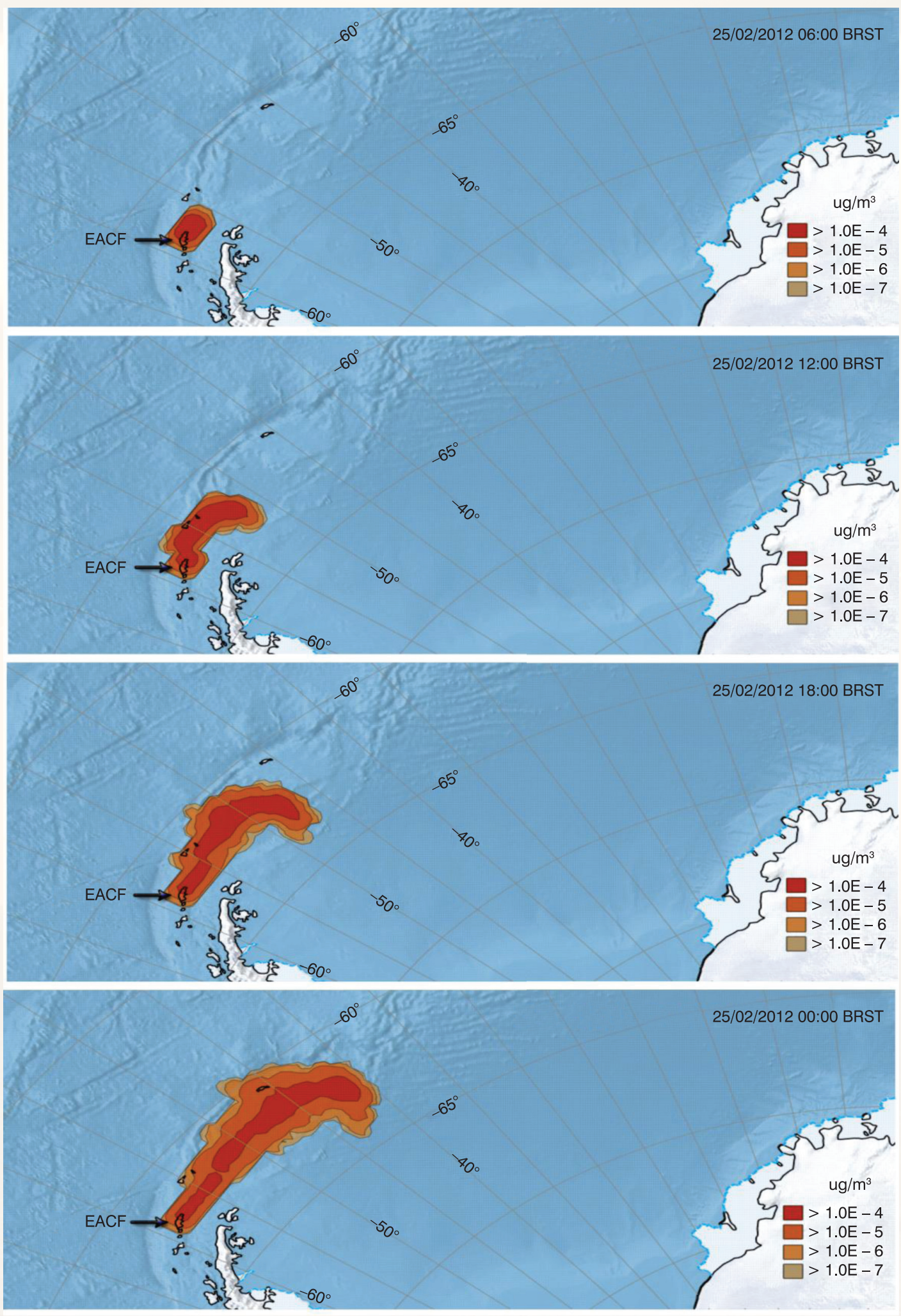

Figure 5. Plume dispersion at Shetland Islands for from February $25^{\text {th }}$ to February $26^{\text {th }}$. (EACF : "Estação Antártica Comandante Ferraz"). 


\section{References}

Leal, M.A.; Joppert, M.; Licínio, M.V.; Evangelista, H.; Maldonado, J.; Dalia, K.C.; Lima, C.; Barros, C.V.; Corrêa, S.M.; Medeiros, G.; Cunha, K.D. (2008). Atmospheric Impacts due to Anthropogenic Activities in Remote Areas: The Case Study of Admiralty Bay/ King George Island/Antarctic Peninsula. Water, Air and Sea Pollution. 188: 67-80.

Vidal, C.M.C. (2008). Descrição da Metodologia do Cálculo da Dispersão de Plumas Aplicada a um Complexo industrial Dissertação de Mestrado- Instituto de Química - UERJ. 